Gregório Edoardo Raphael Selingardi Guardia

\title{
Comunicações Eletrônicas e Dados Digitais no Processo Penal
}

\author{
DISSERTAÇÃO DE MESTRADO
}

\begin{abstract}
Dissertação apresentada à Banca Examinadora da Faculdade de Direito da Universidade de São Paulo, como exigência parcial para obtenção do titulo de MESTRE em Direito, sob a orientação do Prof. Doutor José Raul Gavião de Almeida.

Área de Concentração: Direito Processual Penal.
\end{abstract}

Faculdade de Direito da Universidade de São Paulo

São Paulo

2012 


\section{INTRODUÇÃO}

O contínuo avanço tecnológico experimentado nas últimas décadas proporcionou expressivo aperfeiçoamento das relações interpessoais. A instantaneidade dos processos comunicativos e o caráter eminentemente dinâmico das interações materializadas na chamada sociedade da informação constituem transformações que não podem ser ignoradas pela ciência jurídica.

Cabe ao jurista ponderar cuidadosamente os efeitos destas inovações, que transcendem os limites da técnica e alcançam também o corpo social. O desenvolvimento tecnológico não encontra razão apenas no progresso econômico, presta-se a facilitar o desenvolvimento humano e deve produzir-se em estrita observância aos direitos fundamentais historicamente reconhecidos e consagrados pelo legislador constitucional.

Em tempos correntes, importantes processos de comunicação (escrita ou verbal) e armazenamento de dados aperfeiçoam-se por intermédio dos meios eletrônicos. À medida que o acesso à rede mundial de computadores (internet) se intensifica em progressões geométricas, multiplicam-se também os arquivos intercambiados por internautas e emergem técnicas cada vez mais avançadas de coleta e processamento de dados.

Atividades rotineiras como a navegação e o envio de mensagens eletrônicas realizam-se apenas à custa de imenso trânsito de dados; como pegadas, os signos comutados nestas atuações permitem reconstituir os caminhos percorridos e as ações desenvolvidas na rede. A salvaguarda destas informações afigura-se imprescindível à vida privada e demanda rígida disciplina normativa. Não se trata apenas de impedir que dados de tráfego ou de conteúdo sejam empregados contrariamente ao Direito, mas de assegurar também que, nas situações excepcionais descritas pelo legislador, sirvam para corroborar investigações criminais.

Não se perca de vista que a coleta de fontes de provas no ambiente digital se perfaz no marco constitucional do devido processo legal. Destarte, de rigor 
o equilíbrio entre a preservação das liberdades do cidadão e o interesse público de apurar e punir as condutas criminosas. ${ }^{1}$ A harmonização entre preservação de direitos fundamentais e eficiência na apuração dos delitos ${ }^{2}$ faz-se à luz do único sistema processual condizente com o Estado de Direito - o processo penal de índole acusatória. $^{3}$

Pretende-se neste trabalho, o exame sistemático dos principais meios de busca da prova digital, com o escopo de delimitar o regime jurídico das intervenções nas comunicações eletrônicas e das medidas de apreensão de dados automatizados. Em particular, insta examinar a constitucionalidade destes meios de obtenção de prova à luz dos direitos e garantias individuais que inspiram o ordenamento jurídico brasileiro.

Neste mister, inafastável analisar a disciplina constitucional do sigilo da comunicação de dados (CF, art. $5^{\circ}$, inciso XII) e perscrutar o fundamento legal das autorizações judiciais para a obtenção de informações eletrônicas. Igualmente, há que responder se a inviolabilidade afeta apenas os dados de conteúdo das comunicações, ou se pode também ser estendida aos dados de tráfego.

O capítulo primeiro dedica-se à compreensão dos principais temas que integram o complexo quadro das relações entre Direito e tecnologias informativas. Sob perspectiva eminentemente interdisciplinar, cumpre discorrer

\footnotetext{
${ }^{1}$ ROGÉRIO LAURIA TUCCI expõe, com propriedade, o duplo escopo processualístico-penal: jurisdicionalização da sanção penal e afirmação do ius libertatis (Direitos e Garantias Individuais no Processo Penal Brasileiro, $3^{\text {a }}$ ed., São Paulo, RT, 2009, pp. 28-32).

${ }^{2}$ Sobre as noções de eficiência e garantismo, v. A. S. FERnANDES, Processo Penal Constitucional, $6^{a}$ ed., São Paulo, RT, 2010, pp. 19-21. LUIGI FERRAJOLI aponta três significados diversos para o termo garantismo: "Designa um modelo normativo de direito: precisamente, no que diz respeito ao direito penal, o modelo de "estrita legalidade" SG, próprio do Estado de direitos, que sob o plano epistemológico se caracteriza como um sistema cognitivo ou de poder mínimo, sob o plano político se caracteriza como uma técnica de tutela idônea a minimizar a violência e a maximizar a liberdade e, sob o plano jurídico, como um sistema de vínculos impostos à função punitiva do Estado em garantia dos direitos dos cidadãos (...). Em um segundo significado, "garantismo" designa uma teoria jurídica da "validade" e da "efetividade" como categorias distintas não só entre si mas, também pela "existência ou "vigor" das normas. (...) Segundo um terceiro significado, por fim, 'garantismo' designa uma filosofia política que requer do direito e do Estado o ônus da justificação externa com base nos bens e nos interesses dos quais a tutela ou garantia constituem a finalidade" (Direito e Razão: Teoria do Garantismo Penal, trad. Ana Paula Zomer Sica (et alii), $2^{\mathrm{a}}$ ed., São Paulo, RT, 2006, pp. 785-787). A escolha do "modelo garantista" como esquadro de uma investigação pressupõe a preservação de garantias como método de legitimação para o exercício do poder punitivo. Uma vez instituídas, representam barreiras, vínculos, obstáculos à punição indiscriminada (A. M. GOMES FILHO, $O$ "Modelo Garantista" de Luigi Ferrajoli, Boletim IBCCRIM, n. 58, 1997, p. 6).

${ }^{3}$ Sobre o sistema acusatório $v$. nota 247.
} 
objetivamente sobre noções ${ }^{4}$ de Cibernética, telecomunicações, Informática, liberdade como autonomia recíproca de acesso à informação e comunicações eletrônicas, imprescindíveis à compreensão deste novo espaço do agir humano: o entorno digital.

Em razão das graves ingerências na vida privada que se tem produzido neste entorno, as noveis tecnologias serão apresentadas principalmente a partir dos elementos que conformam o ambiente digital. Por óbvio, há diversas maneiras de apresentar estas importantes questões atinentes à denominada sociedade da informação. Inclusive, há quem preferia associar esta problemática ao contexto globalizado da criminalidade cibernética, ou mesmo, tratar os direitos de internet como autênticos direitos de terceira geração. ${ }^{5}$ Contudo, mais ajustado ao objeto desta Dissertação limitar o estudo aos aspectos relacionados à proteção do direito fundamental à intimidade, cuja afronta faz-se sentir na sociedade contemporânea.

No campo da hermenêutica constitucional (capítulo 2), necessário perquirir relevantes aspectos da vida privada e da proteção da intimidade antecedentes históricos, direito à privacy, hodierna projeção como autodeterminação informativa, teoria das três esferas e inviolabilidade das comunicações - que permitirão opinar sobre a constitucionalidade das interceptações de dados em processos informacionais.

No capítulo terceiro, devem ser conceituados os dados digitais e suas respectivas categorias. Convém também aferir a utilidade dos dados

\footnotetext{
${ }^{4}$ Conquanto não se pretenda imiscuir em questões excessivamente técnicas, pertinentes apenas aos estudos da ciência da computação, de rigor a busca de critérios técnicos para a definição dos conceitos informáticos, justamente para não se descuidar de uma exata compreensão das repercussões jurídicas do fenômeno tecnológico.

${ }^{5}$ Para a doutrina, enquanto os direitos de primeira geração dizem respeito à liberdade, os de segunda geração concernem à igualdade. Os direitos de terceira geração apresentam-se no contexto de uma nova fundamentação, novos instrumentos de tutela e novas formas de titularidade. A. E. PÉREZ-LUÑO enumera expressões similares para o conceito: novos direitos, direitos de solidariedade, direitos da era tecnológica, direitos da sociedade global (La tercera generación de derechos humanos, Navarra, Thomson, 2006, p. 17). Segundo o autor: “ (...) los derechos de la tercera generación tiene como principal valor de referencia a la solidaridad. Los nuevos derechos humanos se hallan aunados entre si por su incidencia universal en la vida de todos los hombres y exigen para su realización la comunidad de esfuerzos y responsabilidades a escala planetaria. Sólo mediante un espíritu solidario de sinergia, es decir, de cooperación y sacrificio voluntario y altruista de los intereses egoístas será posible satisfacer plenamente las necesidades y aspiraciones globales comunes relativas a la paz, a la calidad de vida, o a la libertad informática" (Idem, pp. 34-35).
} 
informáticos, das técnicas de investigação penal e do resguardo de fontes de provas digitais, à luz do paradigma da atuação contraditória e isonômica dos sujeitos processuais.

Sem deixar de contribuir para o aperfeiçoamento da normativa legal vigente, imperioso o exame de duas ordens distintas de incorporação dos dados ao processo: a intervenção no fluxo comunicativo destinada a captar dados e a apreensão física do dispositivo informático que alberga as informações. Como meios de busca de prova, esses procedimentos devem ser estudados de maneira individualizada, a partir de aspectos como conceito, regulação, natureza jurídica, finalidade, condicionantes legais (pressupostos, requisitos e limites), direito de defesa, juízo de proporcionalidade e controle.

Por fim, tecidas as necessárias considerações sobre a conservação, eficácia probatória e valoração dos conteúdos automatizados, impõe-se indagar acerca dos efeitos decorrentes de operações ilícitas perpetradas sobre dados digitais.

Em síntese, inescusável diferenciar os meios fidedignos e necessários de investigação criminal daqueles outros que resultam na produção de provas em desacordo com o direito material. O ordenamento jurídico brasileiro não pode permanecer à margem de ingentes ofensas ao ser humano e à sua eminente dignidade facilitadas pelo progresso tecnológico. 


\section{Conclusões}

1. Os inegáveis progressos da Cibernética na reprodução mecânica da fisiologia animal, dos eventos naturais e das ações humanas, constituem precedentes para o atual estágio da sociedade tecnológica, na qual os novos inventos desempenham atividades essenciais. Sob a perspectiva comparativa entre máquinas e homens, o computador imita as funções neurofisiológicas humanas e a interconexão destes aparelhos eletrônicos em rede possibilita a conformação de territórios fisicamente inexistentes.

2. O entorno digital designa o conjunto de redes onde se encontra todo tipo de informação. As interações neste espaço imaterial subvertem as noções tradicionais de território, tempo e estrutura, tornando necessárias novas ponderações para assegurar a compreensão espacial, cronológica e natural da fluidez e multidimensionalidade das relações jurídicas.

3. A apreensão de conceitos relacionados ao entorno digital tornou-se imprescindível à ciência jurídica contemporânea. $\mathrm{O}$ franco desenvolvimento das tecnologias informativas, operado nas últimas décadas, representa não apenas um fenômeno que reclama imediata resposta legislativa, mas um processo complexo, cujos efeitos alcançam a própria atividade jurisdicional. A plena interação entre informática e telecomunicações modificou por completo o armazenamento de informações; o acesso a pareceres, decisões, normas, e às fontes do Direito em geral, tornou-se imediato. Sem ignorar os benefícios desta transformação, inadmissível sejam abandonadas as técnicas e premissas hermenêuticas em favor da repetição: é preciso velar para que a interpretação jurídica não se converta em mera reprodução mecânica e irrefletida de conteúdos.

4. No entorno virtual os processos comunicativos aperfeiçoam-se de maneira livre e abrangem um amplo contingente de pessoas. O fluxo incessante de dados é capaz de atenuar a própria noção de autonomia e afirmar a liberdade como reciprocidade cada indivíduo pode simultaneamente colher e veicular as informações. 
5. Por redes de comunicação eletrônica designam-se a infraestrutura da comunicação; os serviços de comunicação eletrônicas, destinados à transmissão da informação por meio das infraestruturas de comunicação; e os recursos associados, noveis ferramentas interligadas ao fenômeno telecomunicativo.

6. As redes de comunicação permitem obter, processar e veicular conteúdos em tempo real. Esta evolução afeta diretamente as relações interpessoais e dá ensejo a um novo ciclo cultural, marcado pela estreita afinidade entre o tratamento e a transmissão da informação.

7. A tradição constitucionalista pátria consagra a inviolabilidade de domicílio como liberdade da pessoa, isoladamente considerada, que lhe permite resguardar uma projeção espacial íntima. De outra feita, a liberdade de comunicação refere-se ao exercício das faculdades do próprio espírito, à autonomia e independência do pensamento perante terceiros.

8. Considerada um direito de conteúdo eminentemente negativo, a privacy não figura apenas como faceta do direito de estar só, assume também um viés positivo, enquanto controle direto de informações e da capacidade de comunicá-las e mantê-las para si mesmo.

9. A base axiológica do direito à proteção de dados, reconhecida nas faculdades do titular de dados informáticos - relacionadas ao consentimento, controle, retificação e destruição dos dados -, evidencia o conteúdo da autodeterminação informativa como direito humano vocacionado à autonomia.

10. O emprego de técnicas hermenêuticas (interpretação gramatical, históricoevolutiva e teleológica) e a busca da convergência entre os sentidos, permitem concluir que a expressão "no último caso" (CF, art. 5\%, inciso XII) refere-se às comunicações telefônicas e de dados.

11. Embora distintos o suporte empregado e o canal de circulação da comunicação, tanto a carta como o correio eletrônico são meios de difusão de ideias e pensamentos que utilizam principalmente caracteres escritos. O caráter íntimo da comunicação, 
destinada a um receptor determinado, exige total reserva do conhecimento de terceiros. Por esta razão, o regime da inviolabilidade das comunicações postais igualmente se aplica às interceptações ou acessos a mensagens de correio eletrônico.

12. Concluída a comunicação, não cessa a necessidade de tutela jurisdicional para o conhecimento de seu conteúdo, portanto, não há que diferenciar a proteção das comunicações e a proteção dos dados em si mesmos. A mesma liberdade pessoal que permite manter o pensamento sob recato, impede que o Poder Público legitime a obtenção de informações pessoais sem observar a reserva de jurisdição. Se assim não fosse, restariam comprometidas a harmonia e o equilíbrio entre os Poderes, princípio fundamental da República.

13. Sobre a reserva dos dados de tráfego das comunicações telefônicas em curso e dos dados de comunicações concluídas, incide preponderantemente o art. $5^{\circ}$, XII, da Constituição Federal, que permite derrogar o sigilo apenas mediante autorização judicial. Ou seja, a obtenção dos registros telefônicos e dos dados externos empregados em outras modalidades de comunicação depende de ordem judicial motivada.

14. O dado digital constitui a informação de estrutura numérica e imaterial, processada por sistemas computacionais, destinada a desempenhar uma função e representada em diversos formatos informativos (textos, imagens, áudio e vídeo).

15. Os dados de tráfego das comunicações eletrônicas são informações de estrutura digital, geradas ou tratadas no curso do processo comunicativo, e que diferem do conteúdo material. Como utilizados para o fluxo da informação nas redes, estes dados externos permanecem temporariamente armazenados pelas operadoras de serviço.

16. Os aparelhos eletrônicos e o entorno digital aportam inúmeras informações pessoais sobre os investigados, vítimas ou testemunhas de atos criminosos. Os dados digitais amiúde revelam indícios de autoria e materialidade, informações úteis ao processo e indispensáveis à compreensão dos fatos. 
17. As investigações policiais prospectivas justificam-se apenas quando realizadas em espaços públicos do entorno digital. O emprego de meios de vigilância pessoal afronta direitos fundamentais e não se compatibiliza com o regime constitucional democrático.

18. O acesso aos dados de tráfego afigura-se decisivo na investigação de determinados delitos. O estudo conjugado dos dados externos à comunicação permite investigar a prática de crimes, especialmente quando perpetrados nas redes de computadores, pois a partir deles segue-se o rastro de uma comunicação. Ainda que a obtenção de dados de tráfego possa ter intensidade lesiva menor, a autorização judicial é imprescindível em ambos os casos, assim como a precisa individualização dos aspectos subjetivo e objetivo da medida.

19. A tutela constitucional da inviolabilidade das comunicações aplica-se igualmente aos dados de conteúdo e dados de tráfego. A proteção não se modifica em razão da modalidade de dado pessoal ou do tipo de informação aportada, mas sim, em função da inviolabilidade do meio segundo o qual é transportada.

20. O processo comunicativo no entorno digital ocorre em canal aberto ou fechado. No primeiro caso, disponibiliza-se a informação a qualquer pessoa, independentemente de autorização judicial; no segundo, não há consentimento do usuário para que terceiros tenham acesso ao conteúdo da comunicação.

21. A intervenção refere-se a toda ingerência em processo comunicativo que tenha suporte informático, realizada em canal aberto ou fechado. Por outro giro, a interceptação das comunicações eletrônicas designa a interferência executada por terceiros nos processos comunicativos em canal fechado.

22. As intervenções eletrônicas constituem operações técnicas voltadas a captar o conteúdo comunicativo presente em textos, imagens, sons, ou outro conteúdo digital. A intervenção no fluxo de dados (de conteúdo ou de tráfego), meio de obtenção de prova que tem como característica a restrição de direitos fundamentais, pode ocorrer em canal aberto ou fechado. Neste caso, trata-se de medida excepcionalíssima, pois limita o exercício do direito ao segredo das comunicações, da proteção de dados 
pessoais e da liberdade de pensamento e expressão. Esta medida tem por finalidade viabilizar a investigação dos ilícitos e preservar possíveis fontes de provas.

23. Grande parte dos crimes virtuais transcende os limites espaciais tradicionalmente impostos à atividade delitiva e projetam-se de imediato em diferentes Estados. Uma mesma conduta pode realizar-se simultaneamente em diferentes países, servir-se de meios disponibilizados em lugares completamente distintos e produzir efeitos nas mais variadas partes do globo. A regulação da cyber criminalidade deve pautar-se pela cooperação internacional: ao legislador pátrio não cabe apenas postular a inclusão do Brasil neste cenário, faz-se imprescindível conjugar esforços concretos, que permitam consolidar um sistema transnacional sólido, eficiente e participativo.

24. As intervenções nos processos comunicativos realizados em canal aberto caracterizam-se, principalmente, pela inexigibilidade de resolução judicial que habilite o conhecimento e a apreensão de dados para fins de investigação. A publicidade da informação estriba-se no consentimento do titular, elemento capaz de elidir a aplicação do segredo da comunicação. Incide, no entanto, a proteção específica relativa à autodeterminação informativa.

25. Para que a intervenção nas comunicações eletrônicas e o acesso a dados armazenados em suporte eletrônico conforme-se ao regramento constitucional, a autorização judicial deve estar devidamente fundamentada e atender a finalidade específica, prevista em lei. A licitude destes meios de busca de prova depende da observância dos limites objetivos, subjetivos e temporais, da preservação do exercício do direito de defesa do investigado e do controle judicial da execução da diligência.

26. A intervenção nas comunicações eletrônicas e a busca e apreensão de aparelho digital exigem juízo de proporcionalidade: averiguada a inexistência de outros meios menos lesivos aos direitos do investigado (necessidade); avaliada a eficácia da medida para atender o escopo de apuração dos fatos (idoneidade); valoradas as consequências do ato, em relação à estigmatização jurídica e social que sofrerá o inculpado (proporcionalidade em sentido estrito). 
27. O acesso aos dados informáticos de comunicações concluídas ou de dados armazenados em suporte digital concretiza-se mediante cessão ou busca e apreensão das informações. A cessão opera-se por meio de requisição judicial dirigida aos provedores de internet, ou fundada no consentimento do próprio titular dos dados ou de um dos interlocutores da comunicação.

28. A busca e apreensão de aparelho eletrônico constitui diligência investigativa de procura e asseguração de fontes de prova, limitativa de direito individual, destinada a apreender elementos de convicção necessários à prova de infração ou à defesa do réu, decretada sempre mediante autorização judicial.

29. Uma vez retido o equipamento, o sujeito passivo da apreensão sofrerá limitação nas comunicações cotidianas e também em sua atividade laboral. Avalia-se a situação concreta para diferenciar casos em que deve haver a retenção e o transporte do aparelho até a sede do centro operacional da polícia especializada (sobretudo, quando exigido tempo para operações técnicas), ou quando a cópia integral dos dados relevantes para a análise do disco rígido ou dispositivo de memória representa medida suficiente.

30. O exercício do direito de defesa pressupõe o conhecimento dos procedimentos de conservação dos dados e a possibilidade de confrontá-los com os originais. A não alteração dos dados é imprescindível, a exigir que todo procedimento técnico seja realizado nas respectivas cópias.

31. O tratamento consiste na realização, ao menos, de uma das seguintes operações técnicas de caráter automatizado ou não: armazenamento, consulta, utilização, gravação, conservação, elaboração, modificação, bloqueio, cancelamento ou cessão de dados.

32. Para que a conservação de dados digitais não viole o direito à proteção dos dados, se faz necessário definir claramente a finalidade do tratamento; a segurança deve nortear as cautelas de preservação das informações; a medida há que se restringir ao interregno temporal estritamente necessário à consecução dos objetivos que a justificam. 
33. Assegurar autenticidade no ambiente digital significa estabelecer vínculos adequados entre dados e sujeitos. A comprovação da identidade do usuário deve fundar-se em procedimentos acurados, que permitam relacionar indivíduos e conteúdos, até mesmo nos casos em que o mesmo aparelho eletrônico seja compartilhado por diversas pessoas. A credibilidade dos dados depende, sobremaneira, das circunstâncias em que foram obtidos e tratados; por conseguinte, a informação deve submeter-se às verificações inerentes ao contraditório.

34. A inclusão de provas científicas no processo criminal não deve comprometer o livre convencimento judicial ou frustrar o contraditório. Quando admitidos, os elementos probatórios constituídos unilateralmente sujeitam-se ao confronto argumentativo conduzido pelos peritos, ainda que seja diferido. A existência de meios que permitam verificar a credibilidade das provas facilita a cognição e, ao mesmo tempo, reduz as possibilidades de erro judicial.

35. A licitude da fonte de prova digital demanda escorreita gestão dos conteúdos em sua (i) aquisição; (ii) cadeia de custódia; (iii) autenticação; (iv) recuperação de dados temporários; (v) verificação da autenticidade e confiabilidade da prova - enfim, em qualquer etapa do tratamento de dados. 


\section{BIBLIOGRAFIA}

ABOSO, Gustavo Eduardo, ZAPATA, María Florencia, Cibercriminalidad y Derecho Penal, Montevideo-Buenos Aires, Julio César Faira, 2006.

ALEXY, Robert, Teoría de los Derechos Fundamentales, $2^{\mathrm{a}}$ ed., trad. Carlos Bernal Pulido, Madrid, Centro de Estudios Políticos y Constitucionales, 2008.

ALMEIDA JUNIOR, João Mendes, O Processo Criminal Brazileiro, v. II, $2^{\mathrm{a}}$ ed., Rio de Janeiro, Francisco Aves e Cia, 1911.

ALMEIDA, José Raul Gavião de, Anotações acerca do direito à privacidade, in J. Miranda, Marco Antonio Marques da Silva (orgs.), Visão Luso-Brasileira da Dignidade Humana, 2a ed., São Paulo, Quartier Latin, 2009.

, O interrogatório à distância, São Paulo, Tese de Doutorado, 2000.

ÁLVAREZ GARCIA, Francisco Javier, El acceso por parte de las fuerzas y cuerpos de seguridad del estado a ficheros de datos personales, in Ernesto Pedraz Penalva (coord.), Protección de datos y proceso penal, Madrid, La ley, 2010.

AMODIO, Ennio, Libero convincimento e tassatività dei mezzi di prova: un approccio comparativo, in Rivista italiana di Diritto e Procedura Penale, XLII, n. 1, Milano, 1999.

ARANTES FILHO, Marcio Geraldo Britto, A interceptação de comunicação entre pessoas presentes como meio de investigação de prova no Direito Processual Penal brasileiro, São Paulo, Dissertação de Mestrado, 2011.

ARAUJO, Jose Laercio, Intimidade, Vida Privada e Direito Penal, São Paulo, Habeas, s/d.

ARENAS RAMIRO, Mónica, El derecho fundamental a la protección de datos personales en Europa, Valencia, Tirant lo Blanch, 2006. 
ARENDT, Hannah, Entre o passado e o futuro, trad. Mauro W. Barbosa de Almeida, São Paulo, Perspectiva, 1979.

AVOLIO, Luiz Francisco Torquato, Provas ilícitas: interceptações telefônicas, ambientais e gravações clandestinas, $4^{\mathrm{a}}$ ed., São Paulo, RT, 2010.

BACHELET, Olivier, La hiérarque des preuves, in Geneviève Giudicelli-Delage (org.), Les Transformations de L'administration de la preuve pénale, Paris, Société de Législation Comparée, 2006.

BADARÓ, Gustavo Henrique Righi Ivahy, Direito Processual Penal, tomo I, São Paulo, Elsevier, 2008.

, Interceptação de comunicações telefônicas e telemáticas: limites ante o avanço da tecnologia, in J. Corrêa de Lima e Rubens R. R. Casara (coords.), Temas para uma Perspectiva Crítica do Direito, Rio de Janeiro, Lumen Juris, 2010.

BALLESTEROS MOFFA, Luis Ángel, La Privacidad Electrónica: internet en el centro de protección, Valencia, Tirant lo blanch, 2005.

BANDEIRA, Gustavo, A interceptação do fluxo de comunicações por sistemas de informática e sua constitucionalidade, in Revista de Direito do TJ/RJ, n. 55, 2003.

BARBALHO, João, Constituição Federal Brasileira: Commentarios, Rio de Janeiro, F. Briguet e cia. Editores, 1924.

BARRAGÁN, Julia, Informática y Decisión Jurídica, México, Fontamara, 2000.

BARros, Marco Antonio de, A Busca da Verdade no Processo Penal, São Paulo, RT, 2002.

, Processo Penal Impulsionado pela Tecnologia: A Investigação Criminal Realizada com Novos Meios Tecnológicos e a Iminente Semi-Informatização do Procedimento Penal Anunciada pela Lei 11.419/2006, São Paulo, Tese, 2008. 
BARROS, Suzana de Toledo, O Princípio da Proporcionalidade e o Controle de Constitucionalidade das Leis Restritivas de Direitos Individuais, Brasília, Brasília Jurídica, 1996.

BASTOS, Celso Ribeiro, MARTINS, Ives Gandra, Comentários à Constituição do Brasil, v. 2, São Paulo, Saraiva, 1989.

BASTOS, Celso Ribeiro, MEYER-PFLUG, Samantha, A interpretação como fator de desenvolvimento e atualização das normas constitucionais, in V. Afonso da Silva (org.), Interpretação constitucional, São Paulo, Malheiros, 2007.

BECHARA, Fábio Ramazzini, MANZANO, Luís Fernando de Moraes, Crime Organizado e Terrorismo nos Estados Unidos da América, in J. R. Gavião de Almeida, A. Scarance Fernandes, M. Zanoide de Moraes (orgs.), Crime organizado: aspectos processuais, São Paulo, RT, 2009.

BELTRÁN, Jordi Ferrer, La Valoración Racional de la Prueba, Madrid-BarcelonaBuenos Aires, Marcial Pons, 2007.

BRANDEIS, Louis, WARREN, Samuel D, The right to privacy, Harvard Law Review, v. IV, n. 5, dec. 1890.

BRENNER, Susan W., Cybercrime Metrics: Old wine, new bottles?, Virginia Journal of Law \& Technology Association, v. 9, n. 13, University of Virginia, 2004.

BULOS, Uadi Lammêgo, Constituição Federal anotada, 7ª ed., São Paulo, RT, 2007.

CARIDI, Gianfranco, Metodologia e Tecniche Dell'Informatica Giuridica, Milano, Giuffrè, 1989.

CASEY, Eoghan, Digital evidence and computer crime: forensic science, computers and the internet, New York, Elsevier, 2011. 
CASTANHO DE CARVALHO, Luis Gustavo Grandinetti, Processo Penal e Constituição: Princípios Constitucionais do Processo Penal, $4^{\mathrm{a}}$ ed., Rio de Janeiro, Lumen Juris, 2006.

CASTRO, Ernesto M. de Melo, Algorritmos, São Paulo, Musa, 1998.

CERVINI, Raul, GOMES, Luiz Flávio, Interceptação telefônica: Lei 9.296, de 24.07.96, São Paulo, RT, 1997.

CHIAVARIO, Mario, Diritto Processuale Penale, 5a ed., Milano, UTET, 2012.

COSTA, Helena Regina Lobo, LEONARDI, Marcel, Busca e apreensão e acesso remoto a dados em servidores, Revista Brasileira de Ciências Criminais, n. 88, v. 19, 2011.

COSTA, Sara, A Proteção de Dados Pessoais na Internet, in Revista Jurídica, v. VI, Universidade Eduardo Mondlane, set., 2004.

COSTA JÚNIOR, Paulo José, $O$ direito de estar só: a tutela penal do direito à intimidade, $3^{\mathrm{a}}$ ed., São Paulo, Siciliano, 2004.

CRETElla JÚNIOR, José, Comentários à Constituição de 1988, v. I, Rio de Janeiro, Forense, 1997.

DAVARA RODRIGUEZ, Miguel Ángel, Manual de Derecho Informático, Navarra, Thomson Aranzadi, 2008.

DELMAS-MARTY, Mireille, Il diritto penale come etica della mondializzazione, Rivista italiana di Diritto e Procedura Penale, XLIX, n. 1, Milano, Giuffrè, 2006.

DELPIAZZO, Carlos E., VIEGA, María José, Lecciones de derecho Telemático, Montevideo, Fundación de Cultura Universitaria, 2004.

DEZEM, Guilherme Madeira, Da prova penal: tipo processual, provas típicas e atípicas, Campinas, Millennium, 2008. 
, BECHARA, Fabio Ramazzini, Captação ambiental de imagens: usos e limites, in A. Scarance Fernandes (org.), Estudos de Processo Penal, São Paulo, Scortecci, 2011.

DIMOULIS, Dimitri, MARTINS, Leonardo, Teoria Geral dos Direitos Fundamentais, São Paulo, RT, 2006.

ESPÍNOLA, Eduardo, Constituição dos Estados Unidos do Brasil, v. II, Rio de Janeiro, Freitas Bastos, 1952.

FANUELE, Chiara, Dati genetici e procedimento penale, Milano, Cedam, 2009.

FEDELI, Ricardo Daniel, POLLONI, Enrico Giulio Franco, PERES, Fernando Eduardo, Introdução à ciência da computação, São Paulo, Thomson, 2003.

FERNANDES, Antonio Scarance, Funções e limites da prisão processual, Revista Brasileira de Ciências Criminais, n. 64, São Paulo, Revista dos Tribunais, 2007.

, O polêmico inciso XII do artigo $5^{\circ}$ da Constituição Federal, Justitia, 64 (197), jul./dez., 2007.

, Processo Penal Constitucional, 6 ed., São Paulo, RT, 2010.

, Reação defensiva à imputação, São Paulo, Saraiva, RT, 2002.

, Reflexões sobre as noções de eficiência e de garantismo no processo penal, in, Antonio Scarance Fernandes, José Raul Gavião de Almeida, Maurício Zanoide de Moraes (coords.), Sigilo no Processo Penal, São Paulo, RT, 2008.

, O sigilo financeiro e a prova criminal, in Joel de Faria Costa, Marco Antonio Marques da Silva (coords.), Direito penal especial, processo penal e direitos fundamentais, São Paulo, Quartier Latin, 2006.

FERRAJOLI, Luigi, Direito e Razão: Teoria do Garantismo Penal, trad. Ana Paula Zomer Sica (et alii), 2a ed., São Paulo, RT, 2006. 
FERRAZ JUNIOR, Tércio Sampaio, A ciência do direito, São Paulo, Atlas, 2006.

, Introdução ao Estudo do Direito, $4^{\mathrm{a}}$ ed., São Paulo, Atlas, 2003.

, A invenção do futuro: um debate sobre a pós-modernidade e a hipermodernidade, in Tércio Sampaio Ferraz Junior (org.), A invenção do futuro, São Paulo, Manole, 2005.

, A Liberdade como autonomia recíproca de acesso à informação, in Marco Aurelio Greco, Ives Gandra da Silva Martins (coords.), Direito e internet: relações jurídicas na sociedade informatizada, São Paulo, RT, 2001.

, Liberdade de Informação e Privacidade ou o Paradoxo da Liberdade, in A. de Almeida Filho (org.), Estado de Direito e Direitos Fundamentais, Rio de Janeiro, Forense, 2005.

, Sigilo fiscal e bancário, in Reinaldo Pizolio, Jayr Viégas Gavalcão Jr. (coords.), Sigilo fiscal e bancário, São Paulo, Quartier Latin, 2005.

FERREIRA, Pinto, Comentários à Constituição brasileira, v. I, São Paulo, Saraiva, 1989.

FLUSSER, Vilém, O mundo codificado: por uma filosofia do design e da comunicação, trad. Raquel Abi-Sâmara, São Paulo, Cosacnaify, 2007.

FROSINI, Vittorio, Il Diritto nella Società Tecnologica, Milano, Giuffrè, 1981.

FROUVILLE, Oliver de, La preuve pénale: internationalisation et nouvelles technologies, Paris, La documentation Française, 2007.

GARCIA MARQUES, LOURENÇO MARTINS, Direito da informática, Lisboa, Almedina, 2000.

GARRIGA DOMÍNGUEZ, Ana, Tratamiento de datos personales y derechos fundamentales, Madrid, Dykinson, 2004. 
GOMES FILHO, Antonio Magalhães, A motivação das decisões penais, São Paulo, RT, 2001.

, O "Modelo Garantista" de Luigi Ferrajoli, Boletim do Instituto Brasileiro de Ciências Criminais, n. 58, 1997.

, Notas sobre a terminologia da prova: reflexos no processo penal brasileiro, in Flávio Luiz Yarshell, Maurício Zanoide de Moraes (orgs.), Estudos em homenagem à Professora Ada Pellegrini Grinover, São Paulo, DPJ, 2005.

GONZÁLEZ-CUÉLLAR SERRANO, Nicolás, Garantías constitucionales de la persecución penal en el entorno digital, in J. L. Gómez Colomer (coord.), Prueba y Proceso Penal, Valencia, Tirant lo Blanch, 2008.

GONZÁlEZ LÓPEZ, Juan José, Los Datos de Tráfico de las Comunicaciones Electrónicas en el Proceso Penal, Madrid, La ley, 2007.

, Infiltración policial en Internet: Algunas consideraciones, in Revista del Poder Judicial, n. 85, Consejo General del Poder Judicial, 2007.

, Utilización en el proceso penal de datos vinculados a las comunicaciones electrónicas recopilados sin indicios de comisión delictiva, in Ernesto Pedraz Penalva (coord.), Protección de datos y proceso penal, Madrid, La ley, 2010.

GUERRA FILHO, Willis Santiago, Principio da proporcionalidade e devido processo legal, in V. Afonso da Silva (org.), Interpretação constitucional, São Paulo, Malheiros, 2007.

, Ensaios de Teoria Constitucional, Fortaleza-Ceará, Imprensa Universitária da Universidade Federal do Ceará, 1989.

GRINOVER, Ada Pellegrini, FERNANDES, Antonio Scarance, GOMES FILHO, Antonio Magalhães, As Nulidades no Processo Penal, 10ª ed., São Paulo, RT, 2007. 
GRINOVER, Ada Pellegrini, Liberdades Públicas e Processo Penal: as interceptações telefônicas, $2^{\mathrm{a}}$ ed., São Paulo, RT, 1982.

, Novas Tendências do direito processual, Rio de Janeiro, Forense Universitária, 1990.

GUZMÁN, Nicolás, La Verdad en el Proceso Penal, Buenos Aires, Editores del Puerto, 2006.

HASSEMER, Winfried, Oportunidades para la privacidad frente a las nuevas necesidades de control y las tecnologías de la información, trad. Alfredo Chirino Sánchez, in Nueva Doctrina Penal, Buenos Aires, Editores del Puerto, 1999.

HEGEL, Georg Wilhelm Friedrich, Lineamenti di filosofia del diritto, trad. Francesco Messineo, Roma, Laterza, 1979.

HERNÁN ORTIZ, Ana Isabel, La violación de la intimidad en la protección de datos personales, Madrid, Dykinson, 1998.

HERRERA BRAVO, Rodolfo, NUÑEZ ROMERO, Alejandra, Derecho Informático, San Martín, La Ley, 1999.

KELSEN, Hans, Teoria pura do direito, trad. João Baptista Machado, São Paulo, Martins Fontes, 2000.

KIM, Joon Ho, Cibernética, ciborgues e ciberespaço: notas sobre as origens da cibernética e sua reinvenção cultural, in Horizontes Antropológicos, v. 10, n. 21, Porto Alegre, jan./jun., 2004.

KORSHUNOV, Yu, M., Fundamentos Matemáticos de la Cibernética, trad. Roberto Lanier Alvarez, Moscú, Editorial Moscú, s/d.

LAFER, Celso, Brasil: dilemas e desafios na política externa, São Paulo, Estudos Avançados, v. 14, n. 38., jan./abr., 2000. 
, A Constituição de 1988 e as Relações Internacionais: reflexões sobre o art. $4^{o}$, in Celso Lafer (org.), A internacionalização dos direitos humanos: Constituição, racismo e relações internacionais, Barueri, Manole, 2005.

, Filosofia do direito e princípios gerais: considerações sobre a pergunta "o que é a filosofia do direito”, in A. Caffé Alves (et alii), O que é a Filosofia do Direito?, Barueri, Manole, 2004.

LANCHARRO, Eduardo Alcalde, LOPEZ, Miguel Garcia, FERNANDEZ, Salvador Peñeuelas, Informática Básica, trad. Ségio Molina, São Paulo, McGraw-Hill, 1991.

LARONGA, Antonio, Le prove atipiche nel Processo Penale, Milano, CEDAM, 2002.

LOSANO, Mario, Giuscibernetica: machinne e modelli cibernetici nel diritto, Torino, Einaudi, 1969.

, Lições de Informática Jurídica, São Paulo, Resenha Tributária, 1974.

, Modelos teóricos, inclusive na prática: da pirâmide à rede, in Revista do IASP, ano 8, n. 16, jul./dez., 2005.

LUCCA, Newton de, Títulos e contratos eletrônicos: o advento da informática e seu impacto no mundo jurídico, in Newton de Luca, A. Simão Filho (orgs.), Direito \& Internet: aspectos jurídicos relevantes, São Paulo, Quartier Latin, 2005.

LUPÁRIA, Luca, ZICCARDI, Giovanni, Investigazione Penale e Tenologia Informatica, Milano, Giuffrè, 2007.

MACHADO, André Augusto Mendes, SOUZA, Diego Farjado Maranha Leão, O Crime Organizado na Colômbia, in A. Scarance Fernandes, J. R. Gavião de Almeida, M. Zanoide de Moraes (orgs.), Crime organizado: aspectos processuais, São Paulo, RT, 2009. 
MACHADO, André Augusto Mendes, KEDHI, Andre Pires de Andrade, Sigilo das comunicações e de dados, in Antonio Scarance Fernandes, José Raul Gavião de Almeida, Maurício Zanoide de Moraes (coords.), Sigilo no Processo Penal: Eficiência e Garantismo, São Paulo, RT, 2008.

MADRID CONESA, Fulgencio, Derecho a la Intimidad, Informática y Estado de Derecho, Valencia, Soler, 1984.

MARÇULA, Marcelo, BENINI FILHO, Pio Armando, Informática: Conceitos e aplicações, $2^{\mathrm{a}}$ ed., São Paulo, Érica, 2007.

MARTÍNEZ DE PISÓN CAVERO, José, El derecho a la intimidad en la jurisprudencia constitucional, Madrid, Civitas, 1992.

MAXIMILIANO, Carlos, Commentarios: Constituição Brasileira, Rio de Janeiro, Jacinto Ribeiro dos Santos editor, 1918.

, Comentários à Constituição Brasileira, v. III, Rio de janeiro, Freitas Bastos, 1948.

MELlo, Celso Antonio Bandeira de, Curso de Direito Administrativo, São Paulo Malheiros, 2000.

MENDES, Gilmar Ferreira, COELHO, Inocêncio Mártires, BRANCO, Paulo Gustavo Gonet, Curso de Direito Constitucional, 4ª ed., São Paulo, Saraiva, 2009.

MESQUITA, Rodrigo Octávio de Godoy Bueno Caldas, A proteção da privacidade nas comunicações eletrônicas no Brasil, São Paulo, Dissertação de Mestrado, 2009.

MILTON, Aristide A., A Constituição do Brazil: notícia, história e texto comentado, $2^{\mathrm{a}}$ ed., Rio de Janeiro, Imprensa Nacional, 1898.

MIRABETE, Julio Fabbrini, Processo Penal, $18^{\circ}$ ed., São Paulo, Atlas, 2007. 
MIRANDA, Francisco Cavalcante Pontes de, Comentários à Constituição de 1946, tomo IV, Rio de Janeiro, Borsoi, 1960.

, Comentários à Constituição de 1967, tomo V, São Paulo, RT, 1968.

MOLES PLAZA, Ramón J, Derecho y control in Internet, Barcelona, Ariel, 2004.

MORAES, Alexandre, Constituição do Brasil interpretada, $6^{\mathrm{a}}$ ed., São Paulo, Atlas, 2006.

MORAES, Maurício Zanoide de, Presunção de inocência no processo penal brasileiro: análise de sua estrutura normativa para a elaboração legislativa e para a decisão judicial, São Paulo, Tese de Livre Docência, 2008.

MORALES PRATS, Fermín, La tutela penal de la intimidad: privacy e informática, Barcelona, Ediciones Destino, 1984.

MORALES ROMERO, Marta Muñoz de, La intervención judicial de las comunicaciones telefónicas y electrónicas, in A. S. Hermida (org.), Investigación y prueba en el proceso penal, Madrid, Colex, 2006.

MORÓN LERMA, Esther, Internet y Derecho Penal: Hacking y otras Conductas Ilícitas en la Red, Navarra, Arazandi, 2002.

MOURA, Maria Thereza Rocha de Assis, A prova por indicios no processo penal, São Paulo, Lumen Juris, 2009.

NERY JUNIOR, Nelson, NERY, Rosa Maria de Andrade, Constituição Federal comentada, $2^{\mathrm{a}}$ ed., São Paulo, RT, 2009.

NUCCI, Guilherme de Souza, Código de Processo Penal comentado, 9a ed., São Paulo, RT, 2009.

OLINET, Maud, MARTIN-CHENUT, Kathia, La preuve Cybernétique, Paris, Société de Législation Comparé, 2006. 
ORWELL, George, 1984, trad. Alexandre Hubner, Heloisa Jahn, São Paulo, Companhia das Letras, 2009.

OST, François, KERCHOVE, Michel Van de, Interprétation, in Archives de Philosofie du Droit, tomo 35, 1990.

PALAZZI, Pablo Andrés, Delitos Informáticos, Buenos Aires, Adhoc, 2000.

PEDRAZ PENALVA, Ernesto, La utilización en el proceso penal de datos personales recopilados sin indicios de comisión delictiva, in E. Pedraz Penalva (org.), Protección de datos y proceso penal, Madrid, La ley, 2010.

PEREIRA, Caio Mário da Silva, Instituições de Direito Civil, v. I, $21^{\mathrm{a}}$ ed., Rio de Janeiro, Forense, 2005.

PÉREZ GIL, Julio, Los datos sobre localización geográfica en la investigación penal, in Ernesto Pedraz Penalva (coord.), Protección de datos y proceso penal, Madrid, La ley, 2010.

, Investigación Penal y Nuevas Tecnologías: Algunos de los Retos Pendientes, in Revista Jurídica de Castilla y León, n. 7, out. 2005.

, Medidas de investigación y de aseguramiento de la prueba en el Convenio sobre el Cibercrimen, in Actualidad penal: Revista semanal técnico-jurídica de derecho penal, n. 36, Madrid, La ley, 2003.

PÉREZ-LUÑO, Antonio-Enrique, La tercera generación de derechos humanos, Navarra, Thomson, 2006.

PITOMBO, Cleunice Bastos, Da busca e da apreensão no Processo Penal, $2^{\mathrm{a}}$ ed., São Paulo, RT, 2005.

PITOMBO, Sérgio, Do sequestro no processo penal brasileiro, São Paulo, Bushatsky, 1973. 
QUÉMÉNER, Myriam, CHARPENEL, Yves, Cybercriminalité: Droit pénal appliqué, Paris, Economica, 2010.

REALE, Miguel, Filosofia do Direito, 6ª ed., v.1, São Paulo, Saraiva, 1972.

. Invariantes axiológicos, in Estudos avançados, v. 15, n. 13, São Paulo, USP, 1991.

REBOLlO DELGADO, Lucrecio, Derechos Fundamentales y Protección de Datos, Madrid, Dykinson, 2004.

RODRIGUES, Benjamim Silva, A monitorização dos fluxos informacionais $e$ comunicacionais, v. II, Coimbra, Dissertação de Mestrado, 2009.

RODRÍGUEZ LAINZ, José Luis, Intervención judicial en los datos de tráfico de las comunicaciones, Barcelona, Bosch, 2003.

ROMEO CASABONA, Carlos M, La intimidad y los datos de carácter personal como derechos fundamentales y como bienes jurídicos penalmente protegidos, in Revista de direito da Universidade Estácio de Sá, n. 6, v. 7, Rio de Janeiro, Universidade Estácio de Sá, 2004.

, Tendencias actuales sobre las formas de protección jurídica ante las nuevas tecnologías, in Revista del Poder Judicial, n. 31, set-1993.

SAAD, Marta, O direito de defesa no inquérito policial, São Paulo, RT, 2004.

SARMENTO E CASTRO, Catarina, Privacidade e proteção de dados em rede, Lisboa, Associação Portuguesa de Direito Intelectual, 2006.

SCALISI, Antonio, Il diritto alla riservatezza, Milano, Giuffrè, 2002.

SCARPELLI, Uberto, Ética jurídica sin verdad, Ciudad de México, Fontamara, 2007. 
SILVA, José Afonso da, Comentário contextual à Constituição, $4^{\mathrm{a}}$ ed., São Paulo, Malheiros, 2007.

. Curso de Direito Constitucional Positivo, 25ª ed., São Paulo, Malheiros, 2005.

SILVA, Virgílio Afonso da, Direitos Fundamentais, 2a ed., São Paulo, Malheiros, 2010.

. Interpretação constitucional e sincretismo metodológico, in V. Afonso da Silva (org.), Interpretação constitucional, $1^{\text {a }}$ ed., São Paulo, Malheiros, 2007.

STAINES, Sarah, Data Protection Act Guidelines - a Practical Summary, in United Kingdom Law Articles in English, Pictons Solicitors LLP, May 2004, http://vlex.com/vid/29346721 (acesso em 30 set. 2010, h. 18:20).

STERN, Enrique, El sentido de la privacidad, la intimidad y la seguridad en el mundo digital: ámbitos y limites, in Cuaderno del Instituto vasco de criminología, $\mathrm{n}$. 21, San Sebastián, 2007.

STRECK, Lênio Luiz, As interceptações telefônicas e os direitos fundamentais, $2^{\mathrm{a}}$ ed., Porto Alegre, Livraria dos Advogados, 2001.

TARANTINO, Antonio, Elementi di Informatica Giuridica, Milano, Giuffrè, 1998.

TARUFFO, Michele, La prueba de los hechos, trad. Jordi Ferrer Beltrán, Madrid, Trotta 2002.

TÉLLEZ AGUILERA, Abel, Nuevas Tecnologías - Intimidad y Protección de Datos, Madrid, Edisofer, 2001.

TORNAGHI, Hélio, Instituições de Processo Penal, v. 3, $2^{\mathrm{a}}$ ed., São Paulo, Saraiva, 1978.

TOURINHO FILHO, Fernando da Costa, Manual de Processo Penal, 9a ed., São Paulo, Saraiva, 2007. 
TUCCI, Rogério Lauria, Direitos e Garantias Individuais no Processo Penal Brasileiro, $3^{\text {a }}$ ed., São Paulo, RT, 2009.

UBERTIS, Giulio, Argomenti di Procedura Penale, Milano, Giuffrè, 2002.

, Argomenti di Procedura Penale, v. III, Milano, Giuffrè, 2011.

UICICH, RODOLFO D, El derecho a la intimidad en internet $y$ en las comunicaciones electrónicas, Buenos Aires, Adhoc, 2009.

URBANO DE CASTRILHO, Eduardo de, La valoración de la prueba electrónica, Valencia, Tirant lo blanch, 2009.

ZICCARDI, Giovanni, L'ingresso della computer forensics nel sistema processuale italiano: alcune considerazioni informatico-giuridiche, in Luca Lupária (org.), Sistema penale e criminalità informatica, Milano, Giuffrè, 2008.

ZILLI, Marcos Alexandre Coelho, A Iniciativa Instrutória do Juiz no Processo Penal, São Paulo, RT, 2003.

WALDEN, Ian, Computer crimes and digital investigation, New York, Oxford University Press, 2007. 


\section{Resumo}

Em tempos correntes, importantes processos de comunicação (escrita ou verbal) e armazenamento de informações aperfeiçoam-se por intermédio dos meios eletrônicos. À medida que o acesso à rede mundial de computadores (internet) se intensifica em progressões geométricas, multiplicam-se também os dados intercambiados por internautas e emergem técnicas cada vez mais avançadas de coleta e processamento de informações. Atividades rotineiras como a navegação e o envio de mensagens eletrônicas realizam-se apenas à custa de imenso trânsito de informações; como pegadas deixadas pelo caminho, os dados comutados nestas atuações permitem reconstituir os caminhos e atividades empreendidos na rede. A salvaguarda destas informações afigura-se imprescindível à vida privada e demanda rígida disciplina normativa. Não se trata apenas de impedir que dados de tráfego ou de conteúdo sejam empregados contrariamente ao Direito, mas de assegurar também que, em situações excepcionais descritas pelo legislador, sirvam para corroborar investigações criminais.

Pretende-se neste trabalho um exame sistemático dos principais meios de busca da prova digital, com o escopo de delimitar o regime jurídico das intervenções nas comunicações eletrônicas e das medidas de apreensão de dados automatizados. Neste mister, inafastável analisar a disciplina constitucional do sigilo da comunicação de dados (CF, art. $5^{\circ}$, inciso XII) e investigar o fundamento legal das autorizações judiciais para a obtenção de informações eletrônicas.

Sob perspectiva eminentemente interdisciplinar, cumpre discorrer sobre noções de Cibernética, telecomunicações, Informática, liberdade como autonomia recíproca de acesso à informação e comunicações eletrônicas, imprescindíveis à compreensão deste novo espaço do agir humano: o entorno digital. No campo da hermenêutica constitucional, necessário perquirir relevantes aspectos da vida privada e da proteção da intimidade - antecedentes históricos, direito à privacy, hodierna projeção como autodeterminação informativa, teoria das três esferas e inviolabilidade das comunicações - que permitirão opinar sobre a constitucionalidade das interceptações de dados em processos informacionais. Em sequência, devem ser conceituados os dados digitais e suas respectivas categorias, as técnicas de investigação penal e o resguardo de fontes de provas digitais. Sem deixar de contribuir para o aperfeiçoamento da normativa legal vigente, de rigor o exame de duas ordens distintas de incorporação dos dados ao processo: a intervenção no fluxo comunicativo destinada a captar dados e a apreensão física do dispositivo informático que alberga as informações. Como meios de busca de prova, esses procedimentos devem ser estudados de maneira individualizada, a partir de aspectos como conceito, regulação, natureza jurídica, finalidade, condicionantes legais (pressupostos, requisitos e limites), direito de defesa, juízo de proporcionalidade e controle. Por fim, tecidas as necessárias considerações sobre a conservação, eficácia probatória e valoração dos conteúdos automatizados, impõe-se indagar acerca dos efeitos decorrentes de operações ilícitas perpetradas sobre dados digitais. 


\section{Resume}

In these days, important communication process (written or verbal) and information storage improve through electronic means. While the access to the computer worldwide web (internet) grows in geometrical progression, it also increases the number of webusers data and more and more advanced technics of gathering and processing information emerge. Routine activities such as sailing or sending electronic messages only happen due to the vast transit of information; like footprints left on the way, the data commutated in these actions allow to re-establish the ways and activities undertaken in the web. The security of these information figures indispensable to private life and demands a severe normative discipline. It is not only a matter of preventing that traffic or contents data may be used against the law. But also to assure that, in exceptional situation described by the legislator, it can be useful to confirm criminal investigation.

This work intends a systematic examination of the main ways of searching digital evidence, with the purpose of delimitate the judiciary system of the intervention in electronic and apprehension extent of automation data. So, it must be analysed the constitutional discipline of communication data secrecy $\left(\mathrm{CF}\right.$, art. $5^{\circ}$, inciso XII) and even to investigate the legal foundation of judicial authorization to obtain electronic information.

Under a strictly multidiscipline perspective, one must consider some notions of Cybernetics, telecommunication, Informatics, freedom as reciprocal autonomy access to electronic information and communication, which are essential to understand this new area of human act; the digital place. In the field of constitutional interpretation of law, it is necessary to scrutinize considerable aspects of private life and intimacy protection - historical antecedents, privacy right, actual projection such as informative self-determination, three sphere theory and inviolability of communication - so that they will permit to express an opinion about the constitutionality of interception data in informative proceedings. Sequentially, conceptualize the digital data and their respective categories, penal investigation technics and the protection of digital evidence sources. There may be a cooperation to a better improvement of the effective legal normative, an accurate examination of two different disposition of data incorporation to the process, the intervention in the communicative flow just to receive data and physical apprehension of the informatic device which contains information. As a quest in resources of proof, these proceedings must be examined in a individual way, starting with the aspects such as concept, regulation, juridical nature, finality, legal conditioning (presupposed, requisite and limits), right of defence, judgement of proportionality and control. At last, taken into everything about the conservation, evidential efficiency and the value of automatize contents still we have to enquire about the results of illicit operations perpetrated on digital data. 
